\title{
Ethylene Chlorohydrin
}

National Cancer Institute

\section{Source}

National Cancer Institute. Ethylene Chlorohydrin. NCI Thesaurus. Code C122479.

An organochlorine compound and hazardous substance. Ethylene chlorohydrin is used as a solvent and in the manufacture of a variety of industrial agents. 